\title{
Surgical treatment of falcotentorial meningiomas: a retrospective review of a single-institution experience
}

\author{
Xiaochun Zhao, MD, ${ }^{1}$ Evgenii Belykh, MD, PhD,,2 Colin J. Przybylowski, MD,1 \\ Leandro Borba Moreira, MD, ${ }^{1}$ Sirin Gandhi, MD, ${ }^{1}$ Ali Tayebi Meybodi, MD, ${ }^{1}$ \\ Claudio Cavallo, MD, ${ }^{1}$ Daniel Valli, MD, ${ }^{1}$ Robert T. Wicks, MD, ${ }^{1}$ and Peter Nakaji, MD' \\ 1Department of Neurosurgery, Barrow Neurological Institute, St. Joseph's Hospital and Medical Center, Phoenix, Arizona; and \\ ${ }^{2}$ Irkutsk State Medical University, Irkutsk, Russia
}

\begin{abstract}
OBJECTIVE Meningiomas at the falcotentorial junction represent a rare subgroup of complex meningiomas. Debate remains regarding the appropriate treatment strategy for and optimal surgical approach to these tumors, and surgical outcomes have not been well described in the literature. The authors reviewed their single-institution experience in the management, approach selection, and outcomes for patients with falcotentorial meningiomas.
\end{abstract}

METHODS From the medical records, the authors identified all patients with falcotentorial meningiomas treated with resection at the Barrow Neurological Institute between January 2007 and October 2017. Perioperative clinical, surgical, and radiographic data were retrospectively collected. For patients who underwent the supracerebellar infratentorial approach, the tentorial angle was defined as the angle between the line joining the nasion with the tuberculum sellae and the tentorium in the midsagittal plane.

RESULTS Falcotentorial meningiomas occurred in $0.97 \%$ (14/1441) of the patients with meningiomas. Most of the patients (13/14) were female, and the mean patient age was $59.8 \pm 11.3$ years. Of 17 total surgeries (20 procedures), 11 were single-stage primary surgeries, 3 were two-stage primary surgeries ( 6 procedures), 2 were reoperations for recurrence, and 1 was a reoperation after surgery had been aborted because of brain edema. Hydrocephalus was present in 5 of 17 cases, 4 of which required additional treatment. Various approaches were used, including the supracerebellar infratentorial (4/17), occipital transtentorial/transfalcine (4/17), anterior interhemispheric transsplenial (3/17), parietal transventricular (1/17), torcular (2/17), and staged supracerebellar infratentorial and occipital transtentorial/transfalcine (3/17) approaches. Of the 17 surgeries, 9 resulted in Simpson grade IV resection, and 3, 1, and 4 surgeries resulted in Simpson grades III, II, and I resection, respectively. The tentorial angle in cases with Simpson grade I resection was significantly smaller than in those with an unfavorable resection grade $\left(43.3^{\circ} \pm 4.67^{\circ}\right.$ vs $\left.54.0^{\circ} \pm 3.67^{\circ}, p=0.04\right)$. Complications occurred in 10 of 22 approaches (17 surgeries) and included visual field defects ( 6 cases, 2 permanent and 4 transient), hemiparesis ( 2 cases), hemidysesthesia (1 case), and cerebellar hematoma ( 1 case).

CONCLUSIONS Falcotentorial meningiomas are challenging lesions. A steep tentorial angle is an unfavorable preoperative radiographic factor for achieving maximal resection with the supracerebellar infratentorial approach. Collectively, the study findings show that versatility is required to treat patients with falcotentorial meningiomas and that treatment goals and surgical approach must be individualized to obtain optimal surgical results.

https://thejns.org/doi/abs/10.3171/2019.4.JNS19208

KEYWORDS falcotentorial; meningioma; surgery; oncology

$\mathrm{F}$ ALCOTENTORIal meningiomas are rare, composing $0.3 \%-1.1 \%$ of all intracranial meningiomas..$^{10,18,20,25}$ The term "falcotentorial" describes meningiomas located at the anterior of the junction between the falx and tentorium, 3,7 whereas meningiomas located at the posterior part of the junction (closer to the torcula) are "peritorcular" meningiomas and require separate consideration. ${ }^{3,7}$ Meningiomas of the velum interpositum are another distinct subtype of meningioma located in this area, originating from the double-layered pia of the velum interpositum. ${ }^{4}$ In many cases, the similar location and growth pattern of falcotentorial and velum interpositum

ABBREVIATIONS EVD = external ventricular drain; $\mathrm{mRS}=$ modified Rankin Scale; VFD = visual field defect.

SUBMITTED January 23, 2019. ACCEPTED April 18, 2019.

INCLUDE WHEN CITING Published online August 2, 2019; DOI: 10.3171/2019.4.JNS19208. 
meningiomas do not allow definitive preoperative differentiation between them. ${ }^{16,18}$ "Pineal region" meningiomas are falcotentorial meningiomas that occupy and compress the pineal region; these pineal meningiomas also include velum interpositum meningiomas, according to some researchers. ${ }^{13,19,30}$

Resecting meningiomas located at the anterior portion of the falcotentorial junction is challenging because of their deep location and proximity to critical structures, such as the pineal gland, tectum, and veins of the galenic group. ${ }^{17}$ The occipital transtentorial/transfalcine and supracerebellar infratentorial approaches are usually chosen, but the rate of complications related to the approach itself remains high., ${ }^{2,3,25}$

In this study, we retrospectively assessed the treatment strategy, surgical approach selection, and postoperative outcomes for patients with falcotentorial meningiomas treated at a single institution.

\section{Methods}

The study was performed with approval from St. Joseph's Hospital and Medical Center Institutional Review Board for Human Research, Phoenix, Arizona. The STROBE guidelines for observational cohort studies were followed.

We retrospectively reviewed the medical charts of all patients with meningiomas treated between January 2007 and October 2017 at a single institution (Barrow Neurological Institute, Phoenix, Arizona) and selected all patients with falcotentorial meningiomas, including lesions at the anterior portion of the falcotentorial junction with or without invasion into the pineal region. Preoperative MRI studies were reviewed, and the following variables were recorded and analyzed: Bassiouni type, ${ }^{2}$ Asari type, ${ }^{1}$ tumor diameter, tumor base attachment, displacement and patency of veins of the galenic group, and presence of hydrocephalus. We also reviewed surgical factors, such as approach selection, position selection, and complications. Simpson resection grades ${ }^{29}$ were assigned by an independent neurosurgeon (X.Z.) who reviewed all postoperative MRI as well as the intraoperative observations recorded in operation notes. Presenting symptoms, histopathology, any postoperative radiotherapy, recurrence, preoperative modified Rankin Scale (mRS) score, ${ }^{26} \mathrm{mRS}$ score at the 3-month follow-up, and follow-up duration were assessed. Because patients undergoing multiple surgeries were included in the analysis, follow-up duration, radiotherapy, and recurrence were reported per patient, while the rest of the variables were reported per surgery or approach (for complications).

Additionally, for patients who underwent the supracerebellar infratentorial approach, we measured the tentorial angle on preoperative MRI. The tentorial angle was measured between the line joining the nasion with the tuberculum sellae and the tentorium in the midsagittal plane. ${ }^{11}$

Statistical analysis was performed using PASW Statistics 18.0.0 (SPSS Inc.). We used the independent t-test for all comparisons of numerical variables, and the results are presented as the mean \pm standard deviation (range). A p value $<0.05$ was set as the threshold of significance.

\section{Results \\ General Patient Characteristics}

Patients with falcotentorial meningiomas composed $0.97 \%(14 / 1441)$ of all patients with meningiomas treated at our institution (January 2007-October 2017). Fourteen patients underwent 17 surgeries to treat falcotentorial meningiomas, including 11 single-stage primary surgeries and 3 two-stage primary surgeries (6 procedures); an additional 3 secondary surgeries were reported ( 2 reoperations for recurrence and 1 reoperation after surgery was aborted because of brain edema) for a total of 20 procedures. The mortality rate was $7.14 \%$ ( 1 of 14 patients died). Clinical characteristics for all patients are summarized in Tables 1 and 2. Most patients (13/14) were women, and the mean patient age at surgery was $59.8 \pm 11.3$ years (range $31-77$ years). Preoperative imaging for 1 patient (case 11) was lost, and the tumor diameter was the only information acquired from the operation notes.

\section{Presenting Symptoms}

Headache was the most common preoperative symptom (8/14; Table 1). Two patients (cases 1 and 7) presented with memory deficits caused by obstructive hydrocephalus. Tumor-related visual field defects (VFDs) were present in 2 patients. Other symptoms included extremity weakness, personality changes, imbalance, dizziness, and seizure. One patient (case 3) was admitted with asymptomatic recurrent growth noted on MRI 17 years after the index surgery, which had been performed at another institute.

Two patients underwent multiple surgeries. The patient in case 5, whose primary surgery had been aborted, was admitted for secondary surgery without new neurological symptoms. In the patient in case 14, 2 years after the first surgery, a second surgery was performed for tumor recurrence with newly developed imbalance. Unfortunately, this patient developed postoperative complications after the second surgery and presented again with continuing tumor growth and symptoms of hydrocephalus 1 year after the second surgery.

\section{Preoperative Imaging}

Preoperative MRI studies were available for review for all surgeries except one (16/17; Table 2). In the case missing MRI, available data were extracted from chart records. According to the radiological classification of Bassiouni, 9/16 tumors were type II, 4/16 were type III, 2/16 were type IV, and only $1 / 16$ was type I. According to the Asari classification, 9/16 were the inferior type, 4/16 the superior, $2 / 16$ the anterior, and $1 / 16$ the posterior.

Only 2/16 preoperative MRI studies (cases 3 and 4) showed no vein displacement by the tumors. In the 14 cases with vein displacement, tumor type appeared to be associated with the direction of vein displacement. For meningiomas originating from a unilateral tentorium (Bassiouni type III) or falx (Bassiouni type IV), the veins of the galenic group were usually displaced contralaterally $(4 / 6)$. For meningiomas that originated from the midline (between the two leaflets of falx [Bassiouni type I] or based on bilateral tentorium [Bassiouni type II]), the veins were displaced superiorly or inferiorly $(10 / 10)$. 
TABLE 1. Clinical characteristics of 14 patients who underwent 17 operations for the removal of falcotentorial meningiomas

\begin{tabular}{|c|c|c|c|c|c|c|c|c|c|c|c|c|}
\hline $\begin{array}{l}\text { Case } \\
\text { No. }\end{array}$ & $\begin{array}{l}\text { Op } \\
\text { No. }\end{array}$ & $\begin{array}{l}\text { Age } \\
\text { (yrs), } \\
\text { Sex }\end{array}$ & $\begin{array}{l}\text { Presenting } \\
\text { Symptoms }\end{array}$ & $\begin{array}{l}\text { Preop } \\
\text { mRS } \\
\text { Score }\end{array}$ & $\begin{array}{l}\text { Hydrocephalus } \\
\text { Management \& } \\
\text { Outcome }\end{array}$ & $\begin{array}{l}\text { Simpson } \\
\text { Resection } \\
\text { Grade }\end{array}$ & $\begin{array}{c}\text { Surgical } \\
\text { Complications }\end{array}$ & $\begin{array}{l}\text { Postop } \\
\text { mRS } \\
\text { Score }\end{array}$ & $\begin{array}{l}\text { WHO } \\
\text { Grade }\end{array}$ & RS & $\begin{array}{l}\text { FU } \\
\text { (mos) }\end{array}$ & Recurrence \\
\hline 1 & 1 & $69, \mathrm{~F}$ & Memory issues & 1 & Resolved & III & $\begin{array}{l}\text { Permanent VFD, bal- } \\
\text { ance difficulties }\end{array}$ & 2 & 1 & Yes & 39 & No \\
\hline 2 & 1 & $41, \mathrm{~F}$ & $\begin{array}{l}\text { HA, blurry vi- } \\
\text { sion, It-sided } \\
\text { weakness }\end{array}$ & 1 & $\begin{array}{l}\text { EVD prior to op, } \\
\text { received VPS } \\
\text { subsequently }\end{array}$ & IV & Transient VFD & 1 & I & Yes & 36 & No \\
\hline 3 & 2 & $63, F$ & $\begin{array}{l}\text { None, recur- } \\
\text { rence from op } \\
17 \text { yrs earlier }\end{array}$ & 1 & NA & IV & None & 1 & I & $\mathrm{No}^{*}$ & 2 & No \\
\hline 4 & 1 & $31, \mathrm{~F}$ & $\mathrm{HA}$ & 1 & NA & I & None & 0 & II & No† & 42 & No \\
\hline \multirow[t]{2}{*}{5} & 1 & $65, F$ & $\mathrm{HA}$ & 1 & NA & IV & Transient VFD & 1 & 1 & Yes & 36 & Op aborted \\
\hline & 2 & $67, \mathrm{~F}$ & $\mathrm{HA}$ & 1 & NA & III & None & 1 & II & Yes & 36 & No \\
\hline 6 & 1 & $60, F$ & $\mathrm{HA}$ & 1 & NA & I & None & 0 & I & No & 24 & No \\
\hline 7 & 1 & $59, \mathrm{~F}$ & $\begin{array}{l}\text { Memory issues, } \\
\text { vision loss }\end{array}$ & 1 & ETV prior to op & I & None & 1 & 1 & No & 24 & No \\
\hline 8 & 1 & $60, F$ & $\mathrm{HA}$ & 1 & NA & IV & $\begin{array}{l}\text { Permanent rt-sided } \\
\text { numbness }\end{array}$ & 1 & 1 & No & 32 & No \\
\hline 9 & 1 & $72, \mathrm{~F}$ & Incidental & 0 & $\begin{array}{l}\text { EVD prior to op, re- } \\
\text { solved afterwards }\end{array}$ & IV & None & 0 & I & No & 24 & No \\
\hline 10 & 1 & $60, \mathrm{~F}$ & $\mathrm{HA}$ & 1 & NA & I & Transient VFD & 1 & I & No & 12 & No \\
\hline 11 & 1 & $59, \mathrm{M}$ & $\begin{array}{l}\text { Personality } \\
\text { difficulties, } \\
\text { imbalance }\end{array}$ & 2 & NA & IV & $\begin{array}{l}\text { Transient It-sided } \\
\text { weakness }\end{array}$ & 1 & I & Yes & 72 & No \\
\hline 12 & 1 & $77, \mathrm{~F}$ & Dizziness & 1 & NA & III & $\begin{array}{l}\text { Cerebellar hematoma, } \\
\text { hydrocephalus } \\
\text { (decompression op } \\
\text { performed) }\end{array}$ & 5 & I & No & 24 & No \\
\hline 13 & 1 & $45, \mathrm{~F}$ & Seizure, HA & 2 & NA & II & Permanent VFD & 1 & I & No & 3 & No \\
\hline \multirow[t]{3}{*}{14} & 1 & $61, \mathrm{~F}$ & $\mathrm{HA}$ & 1 & NA & IV & Transient VFD & 1 & II & $\mathrm{No}^{*}$ & 36 & Yes \\
\hline & 2 & $63, F$ & Imbalance & 2 & NA & IV & $\begin{array}{l}\text { Permanent weakness } \\
\text { of lower extremities, } \\
\text { dysarthria }\end{array}$ & 4 & $\|$ & $\mathrm{No}^{*}$ & 36 & Yes \\
\hline & 3 & $64, F$ & $\begin{array}{l}\text { Imbalance, } \\
\text { confusion }\end{array}$ & 3 & $\begin{array}{l}\text { EVD prior to op, pa- } \\
\text { tient died before } \\
\text { VPS }\end{array}$ & IV & No & 6 & II & $\mathrm{No}^{*}$ & 36 & Yes \\
\hline
\end{tabular}

ETV = endoscopic third ventriculostomy; FU = follow-up; HA = headache; NA = not applicable, no hydrocephalus; RS = radiosurgery; VPS = ventriculoperitoneal shunt. ${ }^{*}$ Radiosurgery was recommended in cases 3 and 14, but the patient in case 3 was lost to follow-up after moving to another state and the patient in case 14 refused the procedure because of financial issues.

† Not for the falcotentorial meningioma, but for the 2 meningiomas at other locations.

At presentation, the mean maximum tumor diameter was $3.8 \pm 1.22 \mathrm{~cm}$ (range $2.8-6.1 \mathrm{~cm}$ ) for the patients with no previous surgery. The recurrent tumors (cases 3 and 5 had single recurrences and case 14 had two recurrences) had maximum diameters of $1.6,4.6,5.1$, and $4.5 \mathrm{~cm}$, respectively. In case 5, whose first surgery was aborted, the tumor size increased from 4.1 to $4.6 \mathrm{~cm}$ within 2 years of observation. On available preoperative MRI, 16/16 galenic venous groups were patent, and all were confirmed to be so postoperatively. Among 5/17 surgeries, the patients had signs of hydrocephalus on preoperative MRI. Four of the patients were primary cases, and 1 patient developed hy- drocephalus after a second surgery for a WHO grade II meningioma.

Three patients had additional meningiomas remote from the falcotentorial junction: case 4 had a 3-mm parasagittal meningioma and a 3-mm meningioma at the anterior skull base, case 9 had a 9 -mm falcine meningioma, and case 10 had a 14-mm falcine meningioma.

\section{Preoperative Management}

Five patients presented with radiographic evidence of hydrocephalus; 4 received additional surgery prior to tumor removal, and 1 patient had resolution of the hydro- 


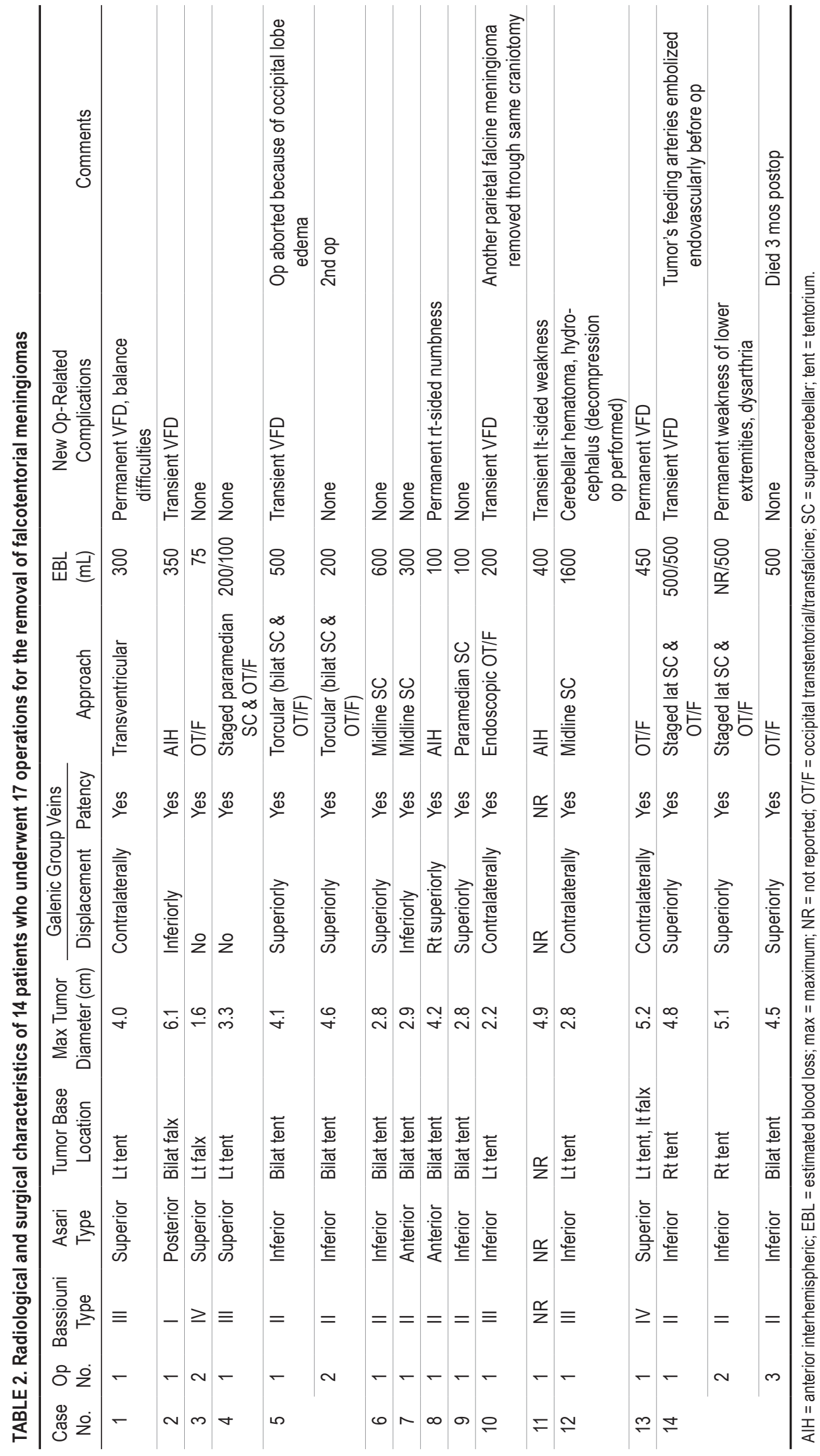


cephalus postoperatively without additional treatment. Prior to surgery, 1 patient (case 7) underwent endoscopic third ventriculostomy that cured the hydrocephalus. Three patients (cases 2, 9, and 14) received an external ventricular drain (EVD). The EVD was successfully removed postoperatively in the patient in case 9 , whereas the other 2 patients (case 2 and case 14 after her third surgery) had symptomatic hydrocephalus that would have mandated shunt placement. One patient (case 2) received a ventriculoperitoneal shunt; however, the other patient (case 14) died before she could receive treatment.

One surgery (1/17) was preceded by angiography with embolization of the tentorial arteries feeding the tumor (case 14).

\section{Surgical Approaches and Resection Grades}

Different approaches were used to access the falcotentorial meningiomas (Table 2): the midline or paramedian supracerebellar infratentorial approach (4/17), occipital transtentorial/transfalcine approach (4/17), anterior interhemispheric transsplenial approach (3/17), and parietal transventricular approach (1/17). A torcular craniotomy (combined supratentorial and infratentorial approach) was used twice in 1 patient (case 5); her first surgery had been aborted after partial tumor removal because of increasing brain edema. At that time, she was neurologically stable except for a transient VFD. She underwent surgery 2 years later using the same approach, and a Simpson grade III resection was achieved with an uneventful recovery. Three (18\%) of the 17 surgeries were staged with the supracerebellar approach followed by the occipital transtentorial/transfalcine approach. The interval between stages was 1 week in 2 cases $(1$ planned and 1 not planned prior to the index surgery) and 3 months (planned) in 1 case. Among the 7 cases using the supracerebellar approach (pure or staged), 2 cases were performed with the patient in the sitting position, 2 with the patient in the park bench position, and 3 with the patient prone.

A Simpson grade IV resection was achieved in 9/17 surgeries; Simpson grade III, II, and I resections were achieved in $3 / 17,1 / 17$, and 4/17 surgeries, respectively.

\section{Management of Multiple Meningiomas}

Among the patients with multiple meningiomas (cases 4,9 , and 10), only 1 patient (case 10) underwent resection of the other meningioma in a single operation (Fig. 1). Surgical removal was not offered to the other 2 patients because of their stability and small tumor size.

\section{Postoperative Complications}

Postoperative complications occurred in 10/17 surgeries. Because most of the new postoperative deficits were related to the trajectory of a surgical approach, the complications were stratified based on the individual approach. For this reason, we accounted for staged and combined procedures that involved two approaches separately. Thus, 9 occipital transtentorial/transfalcine approaches, 9 supracerebellar infratentorial approaches, 3 anterior interhemispheric approaches, and 1 parietal transventricular approach were analyzed for complications (22 approaches, 17 surgeries; Table 3).
Four of 9 patients who underwent the occipital transtentorial/transfalcine approach developed VFDs (1 permanent, 3 transient). One patient developed permanent hemiparesis and dysarthria (case 14, after the second stage of the two-stage supracerebellar infratentorial and occipital transtentorial/transfalcine approaches).

One severe complication of cerebellar hematoma with secondary hydrocephalus occurred in case 12 after a midline supracerebellar infratentorial approach (Fig. 2). Surgical decompression was required after the index surgery, and the patient's quality of life was significantly affected (mRS score increased from 1 to 5). All other (8/9) supracerebellar infratentorial approaches had no complications.

One (case 2) of the 3 patients who had undergone the anterior interhemispheric approach developed a transient VFD, 1 (case 8) had permanent numbness, and 1 (case 11) developed transient hemiparesis.

The 1 patient undergoing a parietal transventricular approach developed permanent VFDs and imbalance postoperatively.

In summary, neurological morbidity was transient after $5(29 \%)$ of 17 surgeries and permanent after $5(29 \%)$ of 17 surgeries.

\section{Histology}

Pathology reports for 3 patients showed WHO grade II meningiomas, including 1 patient (case 5) in whom a WHO grade I meningioma transformed to grade II after 2 years. Eleven other patients had WHO grade I meningiomas, and no WHO grade III meningioma was reported.

\section{Radiosurgery}

Postoperative radiosurgery was recommended to $6(43 \%)$ of the 14 patients. All such patients had Simpson grade III or IV resections, and 2 had WHO grade II meningiomas, including the patient in case 14 who declined radiosurgery because of financial issues. In 1 of the 3 patients with WHO grade II meningiomas, the decision was made not to perform radiosurgery because surgery had achieved a Simpson grade I resection. Three other patients with Simpson grade III or IV resection were not recommended for radiosurgery. One patient (case 12) developed severe complications, and radiosurgery was not considered a meaningful option. In the other 2 patients, the residual tumor volume was minimal, and these patients were followed up with periodic imaging studies. Overall, among the patients who underwent radiosurgery, no recurrence was reported, and the mean mRS score was 1.25 at the last follow-up.

\section{Tentorial Angle}

The relationship between resection rate and tentorial angle in each case using the supracerebellar infratentorial approach is outlined in Table 4. We found that patients with a steep tentorium tended to have unfavorable resection rates. Although 1 patient (case 4) with a steep tentorium had a Simpson grade I resection, this grade was possible only because of the staged procedures (Fig. 3). The first-stage supracerebellar infratentorial approach was insufficient, and some residual tumor was intentionally left at the superior posterior aspect of the resection cavity. The 

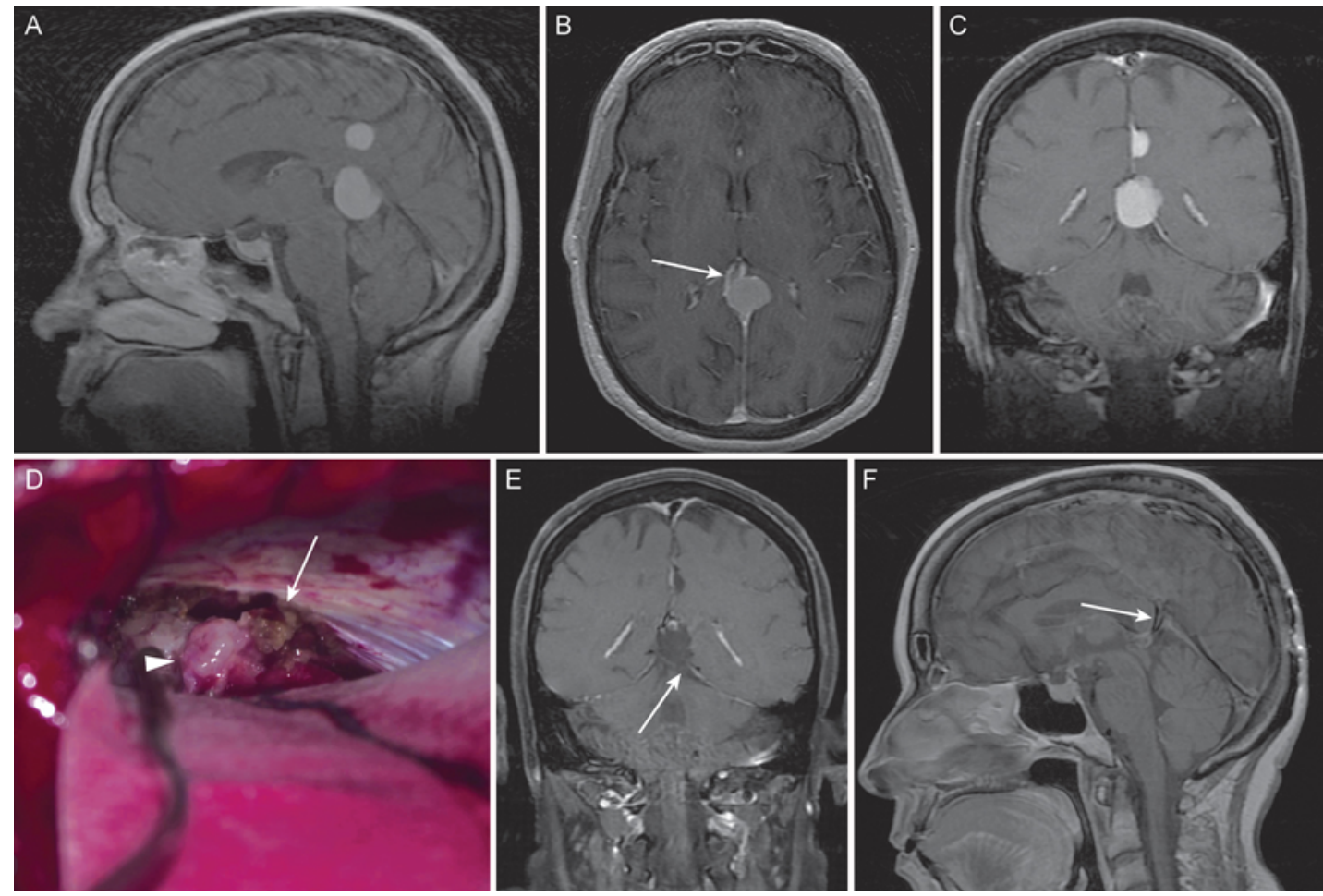

FIG. 1. Case 10. A 60-year-old woman presented with a headache. Preoperative MRI revealed a falcotentorial meningioma based on the left tentorium and an additional smaller falcine meningioma on the left side. A left occipital transtentorial/transfalcine approach was used to exploit the natural corridor between the left occipital lobe and the falx. The second smaller falcine meningioma was resected afterward through the interhemispheric trajectory using the same craniotomy during the same operation. The patient had a transient VFD and demonstrated no recurrence on 12-month follow-up MRI. Preoperative T1-weighted MRI: a sagittal image with contrast enhancement (A) showed two lesions, a smaller falcine and a larger falcotentorial meningioma; an axial image (B) showed that the tumor displaced the tributaries of the vein of Galen (arrow) to the right; and a contrast-enhanced coronal image (C) showed the falcine tumor projecting to the left side. Intraoperative view (D) during the first-stage transtentorial/transfalcine approach shows exposure of the tumor (arrowhead) after the left tentorium was cut (arrow). Postoperative contrast-enhanced T1-weighted MRI: the coronal view $(\mathrm{E})$ showed Simpson grade I resection with removal of the tumor base (cut tentorium, arrow), and patency of the galenic venous system is illustrated on the sagittal (F) image as a flow void (arrow). Figure is available in color online only.

mean tentorial angle in the other cases with a Simpson grade I resection (cases 6 and 7) was significantly smaller than in the cases with a worse resection rate (cases 9 and 12 and the first and second surgeries in case $14 ; 43.3^{\circ} \pm$ $4.67^{\circ}$ vs $54.0^{\circ} \pm 3.67^{\circ}$, respectively, $\mathrm{p}=0.04$ ).

\section{Follow-Up and Outcomes}

The mean patient follow-up was $29 \pm 17.7$ months (range 2-72 months). Postoperative complications worsened the quality of life with an increase of mRS scores after 4/17 surgeries. After 9/17 surgeries, the mRS score remained unchanged, and after 4/17 surgeries, the mRS score was improved. One death among the 14 patients (case 14) occurred 3 months after a third surgery (36 months after the first surgery). This patient had continuous growth of her tumor despite multiple staged resections, the second of which unfortunately resulted in complications that negatively affected her quality of life to a substantial degree.

\section{Discussion}

Falcotentorial meningiomas are technically challenging lesions for which the optimal treatment strategy and approach selection are individualized. Resection of these tumors is complicated by their deep location and proximity to vulnerable anatomical structures, such as the pineal gland, tectum, veins of the galenic group, and medial posterior choroidal arteries. ${ }^{634}$ Meningiomas of a pure falcotentorial location are also rare, with the largest series of 15 cases reported by Qiu et al. in 2014.23

Two classification systems have been proposed for falcotentorial meningiomas: one by Asari et al. ${ }^{1}$ in 1995, which is based on tumor projection and classifies the tumors as anterior, superior, posterior, and inferior types; and the other by Bassiouni et al. ${ }^{2}$ in 2008, which classifies tumors according to tumor base location and includes type I (between the 2 falx leaflets), type II (middle inferior tentorial surface), type III (unilateral tentorium), and type IV (unilateral falx or straight sinus). The Asari and Bassiouni classifications are detailed in Table 5.

\section{Selected Approaches and Complications Observed}

Multiple approaches were used in our case series, with the supracerebellar infratentorial approach and occipital transtentorial/transfalcine approach being the two most 
TABLE 3. Complications stratified by the surgical approach used

\begin{tabular}{|c|c|c|c|c|c|}
\hline \multirow[b]{2}{*}{ Approach } & \multicolumn{5}{|c|}{ Complication } \\
\hline & VFD & Imbalance & Sensory Deficit & Motor Deficit & Hematoma \\
\hline OT/F $(n=9)^{*}$ & $\begin{array}{r}\text { 4/9 (3 transient, } \\
1 \text { permanent) }\end{array}$ & & & $\begin{array}{l}\text { 1/9 (permanent hemiparesis), } \\
\text { 1/9 (dysarthria) }\end{array}$ & \\
\hline SC infratentorial $(n=9) \dagger$ & & & & & $1 / 9$ \\
\hline AlH $(n=3)$ & $1 / 3$ (transient) & & $\begin{array}{l}1 / 3 \text { (numbness, per- } \\
\text { manent) }\end{array}$ & 1/3 (transient hemiparesis) & \\
\hline Transventricular $(n=1)$ & $1 / 1$ (permanent) & $1 / 1$ & & & \\
\hline $\begin{array}{l}n=\text { number of cases. } \\
\text { *All occipital transtentorial/tra } \\
\text { proach. } \\
\text { † All supracerebellar infratent } \\
\text { proach. }\end{array}$ & $\begin{array}{l}\text { Icine approaches, } \\
\text { approaches, inclu }\end{array}$ & $\begin{array}{l}\text { luding pure } \\
\text { g pure med }\end{array}$ & $\begin{array}{l}\text { cipital, staged, or sim } \\
\text { paramedian, staged, }\end{array}$ & $\begin{array}{l}\text { aneous combined with the suprac } \\
\text { d simultaneous combined with the }\end{array}$ & $\begin{array}{l}\text { ebellar ap- } \\
\text { ccipital ap- }\end{array}$ \\
\hline
\end{tabular}

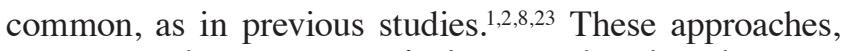
as compared to a transcortical approach, take advantage of the natural corridors created by gravity-assisted brain retraction.
Occipital Transtentorial/Transfalcine Approach and Its Variant

The occipital transtentorial/transfalcine approach exploits the relative paucity of occipital bridging cortical veins and the natural path created by gravity-assisted re-
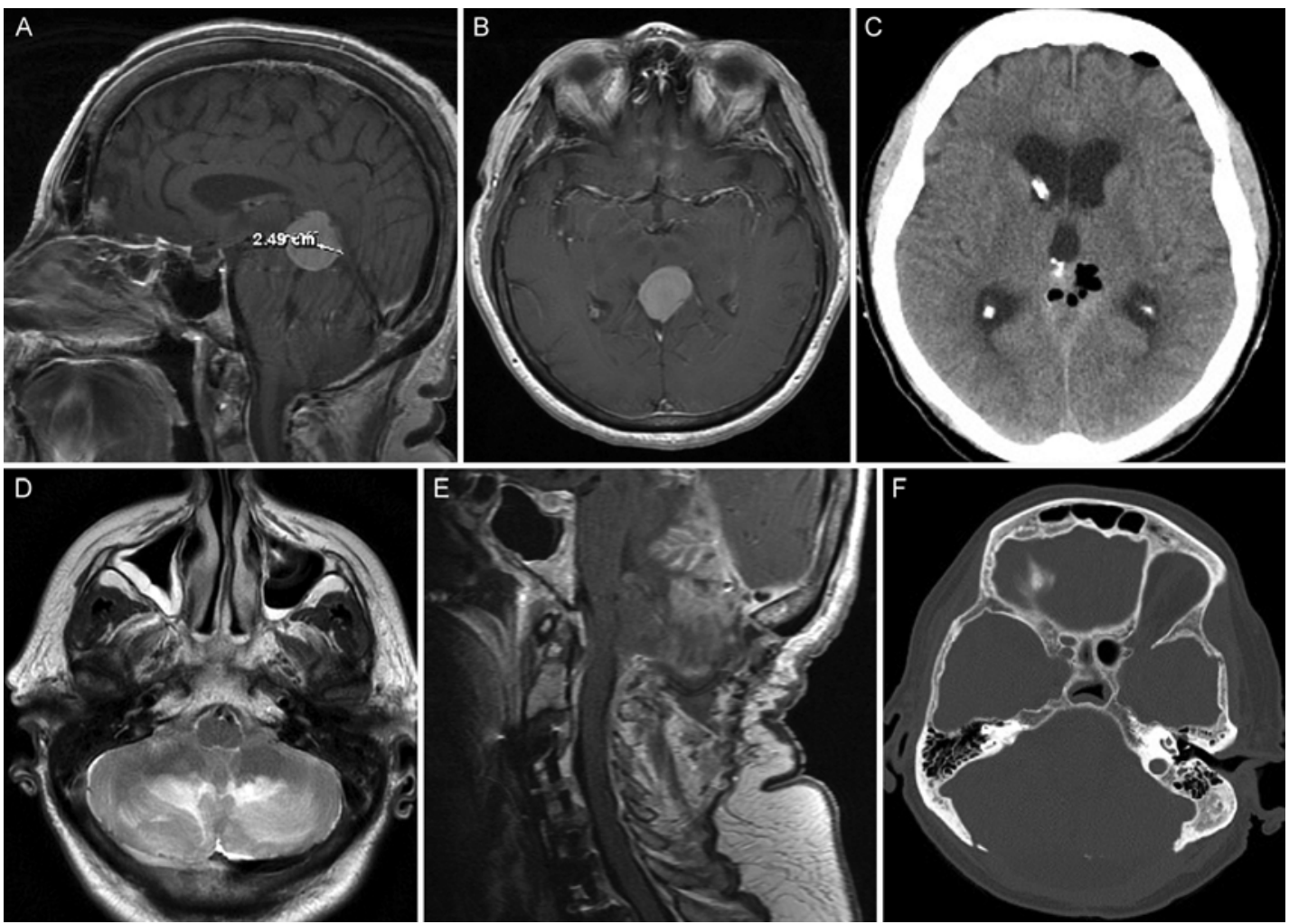

FIG. 2. Case 12. A 77-year-old woman presented with episodes of dizziness. Preoperative sagittal (A) and axial (B) MRI demonstrated an inferior-pointing falcotentorial meningioma. The lesion base was located on the inferior surface of the tentorium on both sides. The diameter was measured as $2.5 \mathrm{~cm}$ on the sagittal section. A midline supracerebellar infratentorial approach was planned. A prone position was selected instead of a sitting position because of the patient's history of patent foramen ovale. A lumbar drain was placed preoperatively to achieve brain relaxation. The cerebellum appeared edematous after tumor resection; therefore, the bone flap was left off. The patient presented with decreased mental status after the operation, with a Glasgow Coma Scale score of 5, and postoperative imaging demonstrated increasing hydrocephalus and swelling cerebellum. A posterior fossa decompression with resection of the infracted cerebellum was performed. The patient was confined to a wheelchair and had an mRS score of 5 at the 24-month follow-up. Postoperative axial CT (C) of the tumor resection cavity showed scattered subarachnoid hemorrhage. Postoperative axial (D) and sagittal (E) MRI demonstrated an edematous cerebellum. Axial CT (F) after posterior fossa decompression showed the large decompressive craniotomy. 
TABLE 4. Summary on tentorial angle and Simpson grade for all falcotentorial meningiomas treated via a supracerebellar infratentorial approach

\begin{tabular}{ccc}
\hline Case No. & Tentorial Angle & Simpson Grade \\
\hline 4 & $49.0^{\circ}$ & $\mathrm{I}^{*}$ \\
\hline 6 & $46.6^{\circ}$ & $\mathrm{I}$ \\
\hline 7 & $40.0^{\circ}$ & $\mathrm{I}$ \\
\hline 9 & $56.7^{\circ}$ & $\mathrm{IV}$ \\
\hline 12 & $53.4^{\circ}$ & $\mathrm{II}$ \\
\hline 14 & $56.8^{\circ}$ & $\mathrm{IV} \dagger$ \\
\hline
\end{tabular}

Case 5 was not included in this analysis as the patient's craniotomy was not a pure supracerebellar approach in a single operation.

* The patient in case 4 underwent staged surgery. The Simpson grade after the first supracerebellar infratentorial approach was IV, and Simpson grade I resection was achieved after the second occipital transtentorial approach.

$\dagger$ The patient in case 14 underwent multiple staged surgeries; the supracerebellar approach was used prior to the occipital approach for both surgeries, and the tentorial angle was the same in the two surgeries. traction of the ipsilateral occipital lobe. Incision of the tentorium allows a direct route to the pineal region. The most common complication risk in the occipital transtentorial/ transfalcine approach is a VFD, which is usually transient (only one such complication among 9 of these surgeries in our study). ${ }^{33}$ The tentorial angle is also important, as a steeper tentorial angle was shown by $\mathrm{Li}$ et al. ${ }^{14}$ to have a higher risk of occipital lobe damage in this approach. Liu and Cohen ${ }^{15}$ used the posterior interhemispheric approach for a patient with a very steep tentorial angle whose occipital lobe was also low set. This approach can be interpreted as a variant of the occipital transtentorial/transfalcine approach when the tentorial alignment is extremely steep, as it provides a similar operative angle.

Goto et al. ${ }^{8}$ asserted that the occipital transtentorial approach resulted in better outcomes in falcotentorial meningiomas with superior extension than those with inferior extension. In our series, however, we were not able to discern a preference for an occipital transtentorial/transfalcine approach for any particular meningioma subtype or growth pattern. Such selection remains biased because of the low number of cases and the personal preference of the surgeon. A pooled multicenter analysis is required to pro-
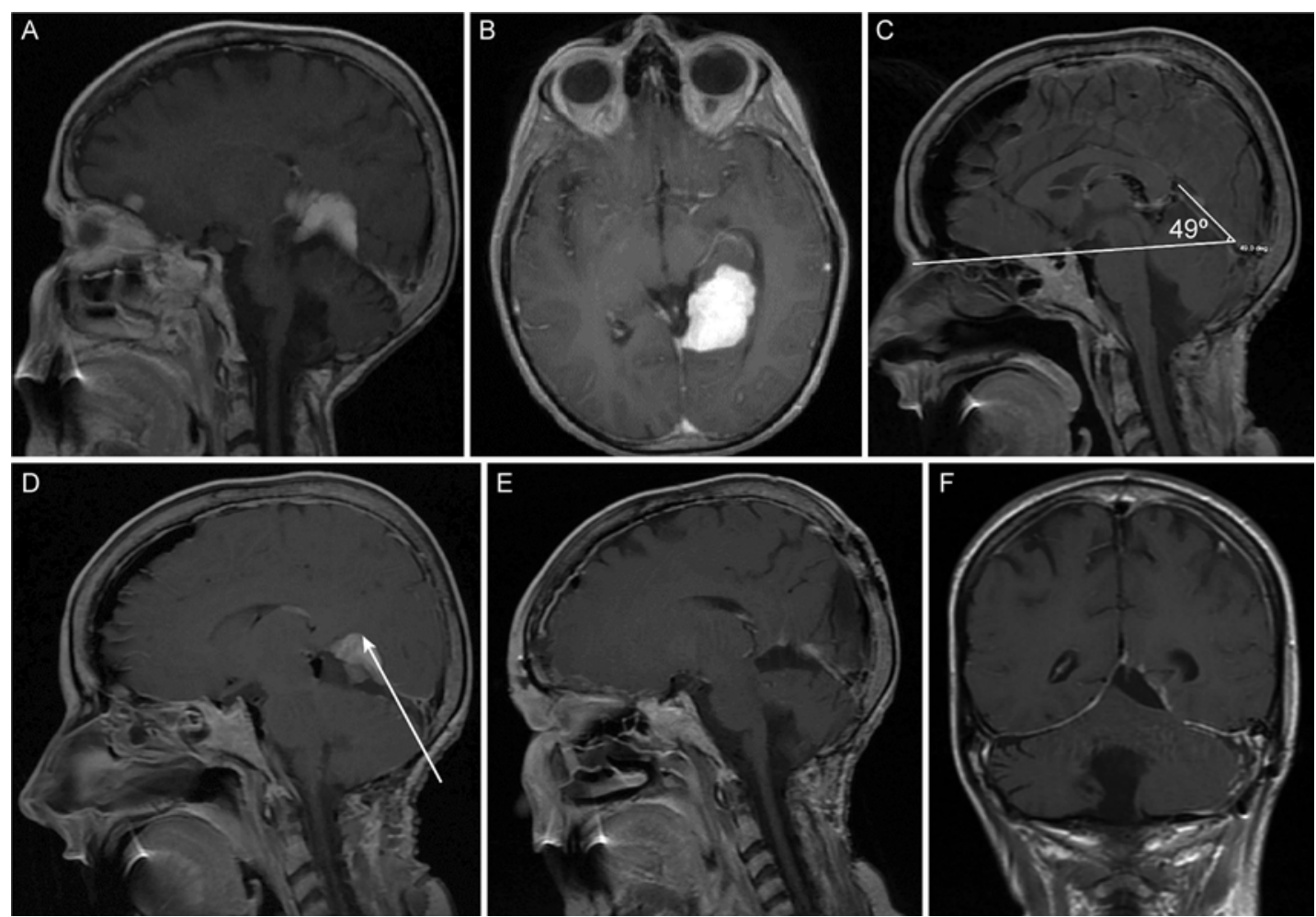

FIG. 3. Case 4. A 31-year-old woman presented with headache and was found to have a falcotentorial meningioma. The lesion base was located on the left tentorium, and the tumor projected superiorly. A stage 1 supracerebellar infratentorial approach was performed first. The superior posterior portion of the tumor projecting into the occipital lobe was left for a second-stage surgery. A stage 2 ipsilateral occipital transtentorial/transfalcine approach was then used to remove the residual tumor. A Simpson grade I resection was achieved, and no complication was encountered postoperatively. The patient had no recurrence on the 42-month follow-up MRI. Preoperative sagittal (A) and axial (B) T1-weighted MRI with contrast enhancement demonstrated a left-sided falcotentorial meningioma projecting superiorly and laterally, while the tentorial angle (C) was measured as $49.0^{\circ}$. Sagittal MRI (D) after stage 1 surgery showed that superior and posterior portions of the tumor required a more upward approach angle (arrow), so a small residual lesion was intentionally left for a second-stage surgery. Sagittal $(\mathbf{E})$ and coronal $(\mathbf{F})$ contrast-enhanced T1-weighted MRI after the second-stage surgery via the occipital transtentorial/transfalcine approach showed a Simpson grade I resection. 
vide a more definitive conclusion. At this stage, however, a tailored individualized approach selection, also incorporating the preference of the surgeon and the facility with a given approach, represents a reasonable option. For example, in case 10, the tumor originated from one side of the tentorium, and the major part of the tumor was infratentorial. In such a case, both a supracerebellar infratentorial approach and an occipital transtentorial/transfalcine approach are feasible. However, the presence of a second tumor and a bridging vein-free zone on the left side favored the occipital transtentorial/transfalcine approach, and both meningiomas were successfully resected through the same craniotomy. We believe that a tumor occupying the infratentorial space can also be accessed effectively through an occipital transtentorial/transfalcine approach by opening the tentorium.

\section{Supracerebellar Approach}

The supracerebellar approach uses the natural space between the superior surface of the cerebellum and tentorium; variants include midline, paramedial, lateral, and extreme-lateral approaches. ${ }^{35}$ The midline supracerebellar approach necessitates the sacrifice of the occipital sinus along with the midline bridging veins, which could have caused venous congestion and resulted in the edema and hemorrhage in case 12 .

The patient position was decided on the basis of multiple factors. The sitting position is unfavorable for patients with a congenital heart defect, such as a patent foramen ovale (case 12). An advantage of the sitting position is that it is associated with greater brain relaxation. Endoscopy is a valuable adjunctive visualization tool for deep and close inspection. The approach selection was made in part on the basis of the attending neurosurgeon's preference and in part on the basis of the needed exposure. Usually, larger craniotomies were performed with the patient prone if a more extensive exposure was anticipated.

We believe that not only the location and projection of the tumor but also the tentorial angle should influence approach selection. Despite the limited number of supracerebellar approach cases $(n=6$; Table 4$)$, we found that patients with Simpson grade I resection had a significantly smaller tentorial angle $(\mathrm{p}=0.04)$ than the patients with other Simpson grades.

The patient in case 4 in our series underwent a supracerebellar infratentorial approach, and the superior posterior portion of the tumor, which invaded the occipital lobe, was inaccessible because it required a more upward approach angle. The decision was made to leave some residual tumor and approach the residual lesion through an occipital transtentorial/transfalcine approach in a second stage 1 week later. On the postsurgical film review, we concluded that the difficulties in reaching the distal part could have been predicted, leading to the option of a staged surgery at the beginning.

Several other studies have also suggested that an infratentorial approach to the supratentorial or pineal regions can be challenging in patients with a steep tentorium, and the occipital transtentorial/transfalcine approach should be favored in such cases. ${ }^{5,9,31}$
TABLE 5. Descriptions of the Asari and Bassiouni classifications

\begin{tabular}{|c|c|}
\hline Classification & Description \\
\hline \multicolumn{2}{|l|}{ Asari* $^{*}$} \\
\hline Superior type & Superior extension above cerebellar tentorium \\
\hline Inferior type & $\begin{array}{l}\text { Inferior extension between great vein of Galen and } \\
\text { straight sinus }\end{array}$ \\
\hline Anterior type & $\begin{array}{l}\text { Anterior extension between inferior sagittal sinus } \\
\text { and great vein of Galen }\end{array}$ \\
\hline Posterior type & Posterior extension along straight sinus \\
\hline \multicolumn{2}{|c|}{ Bassiouni† } \\
\hline Type I & $\begin{array}{l}\text { Origin: btwn leaflets of the falx above the junction of } \\
\text { great vein of Galen with straight sinus } \\
\text { Direction of growth: toward pineal region; displaces } \\
\text { great vein of Galen and internal cerebral veins } \\
\text { inferiorly }\end{array}$ \\
\hline Type II & $\begin{array}{l}\text { Origin: from underneath tentorium near the junction } \\
\text { of vein of Galen with straight sinus } \\
\text { Direction of growth: toward pineal region; pushes } \\
\text { galenic venous system upward }\end{array}$ \\
\hline Type III & $\begin{array}{l}\text { Origin: from paramedian tentorial incisura; hence, } \\
\text { it is lateralized; great vein of Galen lies medial } \\
\text { to tumor }\end{array}$ \\
\hline Type IV $\ddagger$ & $\begin{array}{l}\text { Origin: from falcotentorial junction along straight } \\
\text { sinus } \\
\text { Direction of growth: toward pineal region; displaces } \\
\text { galenic venous system contralaterally }\end{array}$ \\
\hline
\end{tabular}

\section{Anterior Interhemispheric Approach}

The anterior interhemispheric approach was used as a single-stage primary surgery in 3 of our patients. Although the distance to the tumor in this approach is relatively long and requires longer instruments, it is thought that the trajectory minimizes the risk of sacrificing bridging veins and retraction on the visual cortex.$^{32}$ Despite this, transient VFDs occurred in 1 of our patients, and hemiparesis or hemidysesthesia occurred in another 2 , most likely caused by over-retraction, impingement of the bridging veins, or retraction injury to the functional cortex in the interhemispheric fissure.

\section{Torcular Approach}

The torcular approach was used twice in 1 patient (case 5 , whose first operation was aborted after partial resection of tumor because of brain edema and whose second operation was performed 2 years later). This bilateral, combined supratentorial and infratentorial approach has been advocated by several studies ${ }^{24,37}$ for better exposure, although in one series, $100 \%$ of cases developed transient VFDs. ${ }^{24}$

\section{Parietal Transventricular Approach}

The parietal transventricular approach was used in 1 patient (case 1) because the lesion grew superiorly and laterally with thinning of the medial wall of the left ventricle. The permanent VFD was predictable because the lateral 

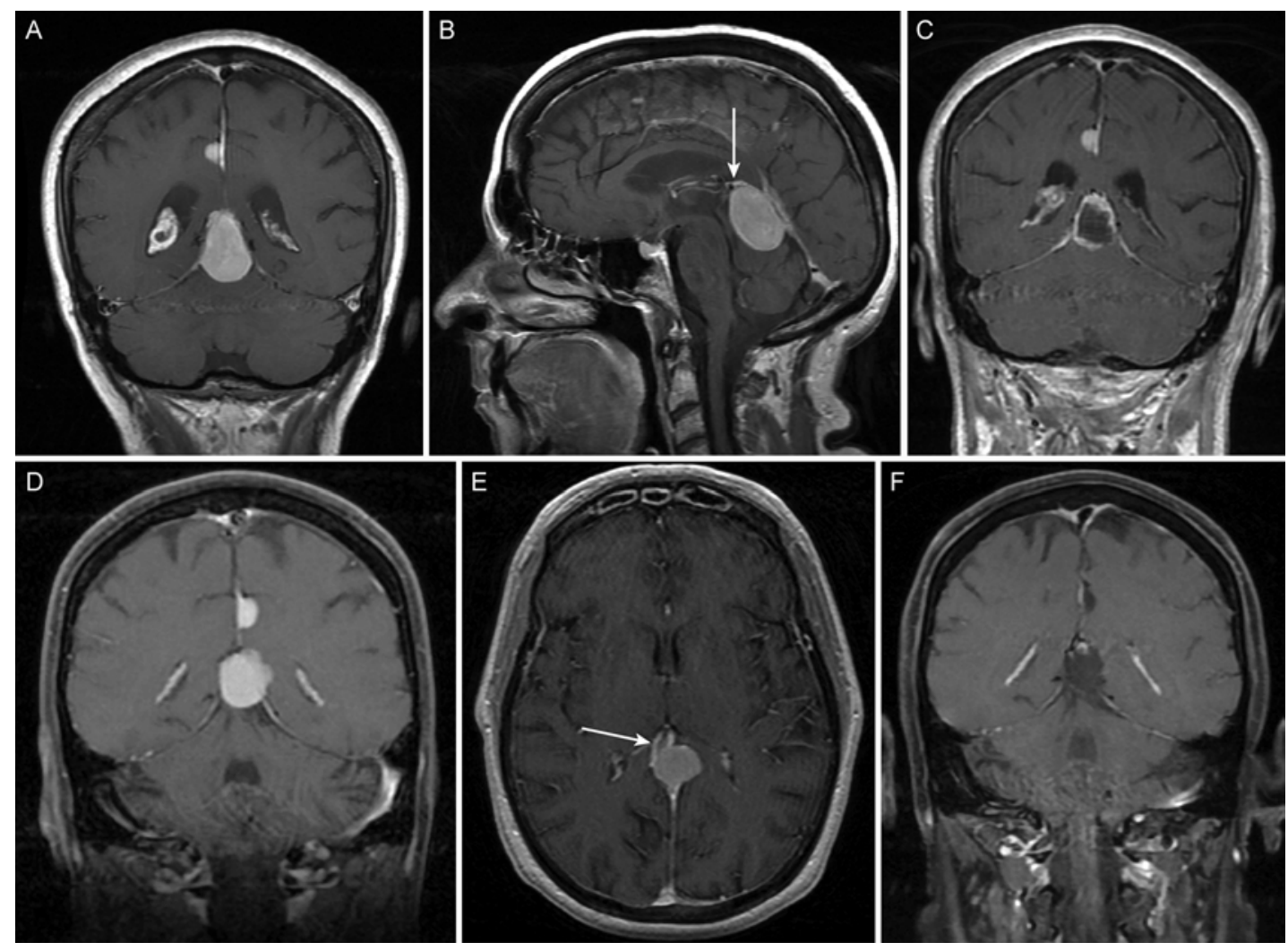

FIG. 4. Case 9. Preoperative coronal (A) and sagittal (B) T1-weighted MRI with contrast enhancement showed the galenic venous system was displaced superiorly (arrow). The postoperative coronal image (C) showed subtotal resection. Case 10. Preoperative coronal (D) and axial (E) T1-weighted MRI with contrast enhancement showed the galenic venous system was displaced contralaterally (arrow). A postoperative coronal image (F) showed that gross-total resection was achieved.

wall of the lateral ventricle, which contains the optic radiation, was transgressed. This approach is rarely reported in the literature, likely because of the fear of damage to the optic radiation.

\section{Staging of Surgery}

Staged surgery may be a reasonable option for the complete removal of complex falcotentorial meningiomas. In this strategy, each approach is used within the safe limits of the working angles. Rather than extending the existing approach and risking critical structures by over-retraction, the remaining parts of a tumor can be safely removed via a separate approach with a more favorable trajectory. Otani et al. ${ }^{21}$ demonstrated that a staged strategy was successful for the safe removal of large pineal region meningiomas ( $\mathrm{n}$ $=4$ ). In our series, 3 staged surgeries were performed in 2 patients (cases 4 and 14) with WHO grade II meningiomas with aggressive growth and adhesion to adjacent structures. The supracerebellar infratentorial approach was always used before the occipital transtentorial/transfalcine approach. The infratentorial space is naturally larger than the supratentorial space, especially in the presence of space-occupying lesions. With a first-stage supracerebellar infratentorial approach, the relatively large infratentorial space can be used when debulking the tumor, and more space and greater maneuverability are subsequently available for the second stage. The risks of unintentional injury while removing remote tumor remnants via a single approach may outweigh the risks of a subsequent surgery.

\section{Individualized Approach Selection}

Although multiple approaches can be selected for falcotentorial meningiomas, an individualized approach selection for each patient should be preferred. Many factors, such as projection of the tumor, individual anatomy of bridging veins, dislocation of the galenic venous system, tentorial angle, and presence of a second tumor, play a role in approach selection.

In our series, cases 9 and 10 (Fig. 4) were almost identical on preoperative imaging. Both patients had 2 meningiomas at the same location, 1 falcotentorial and 1 falcine (Fig. 4A and 4D). As discussed above, the occipital transtentorial/transfalcine approach was selected for case 10, and both meningiomas were successfully removed through a single craniotomy. Unlike in case 10 , whose galenic veins were displaced contralaterally (Bassiouni type III), the veins of case 9 were displaced superiorly (Bassiouni type II), and those veins could be jeopardized as they blocked surgical access through an occipital transtentorial/transfalcine approach. Case 9 also had a very steep tentorial angle, which was an unfavorable factor for a supracerebellar infratentorial approach. However, the supracerebellar infratentorial approach was still selected after balancing the risk of damage to the deep draining veins and the risk 
of incomplete resection. In this case, we did not attempt to remove the second meningioma.

\section{Hydrocephalus}

Hydrocephalus due to aqueductal compression is another concern for patients with falcotentorial meningiomas. In a previous report, the preoperative treatment of hydrocephalus was not recommended as decompression of the aqueduct in the index surgery was expected to restore patency of the CSF pathways. ${ }^{23}$ In our series, $4 / 5$ patients with signs of hydrocephalus received additional treatment. Only 1 patient (case 1) did not receive additional treatment because the ventricle was opened during the transventricular approach. Preoperative management of hydrocephalus can ease brain retraction, facilitate tumor exposure, decrease brain edema, and provide CSF drainage if surgical removal of the tumor does not restore aqueductal CSF flow. Further studies are merited to determine whether a permanent shunt or temporary shunt should be used in cases in which the decompressive operation may relieve the hydrocephalus.

\section{Adjunctive Radiosurgery}

Adjunctive radiosurgery for meningioma can play an essential role in preventing tumor regrowth or controlling recurrence..$^{12,22,36}$ In our series, radiosurgery was recommended to patients with high-grade pathology without Simpson grade I resections. Radiosurgery in patients with unfavorable Simpson grades can be withheld if the residual tumor is small and stable on serial postoperative imaging.

\section{Preoperative Embolization}

Reduced intraoperative blood loss, decreased operative duration, and decreased firmness of the tumor are all theoretical benefits of preoperative embolization, but definitive evidence regarding the effects of preoperative embolization on patient outcome is still lacking. ${ }^{27,28}$

The most common arterial feeders of falcotentorial meningiomas are branches of the tentorial, posterior cerebral, or superior cerebellar arteries. ${ }^{1,10}$ Because the anatomy is such that the tumor's dural base can be accessed and coagulated, we used endovascular embolization infrequently in our series.

\section{Limitations of the Study}

The retrospective nature and limited number of cases are the main limitations of this study. In the supracerebellar infratentorial approach, a steep tentorial angle is an unfavorable factor. However, multiple factors can affect the Simpson grade and outcome, which can confound the results. Because of the low incidence of falcotentorial meningiomas, multicenter studies or meta-analyses are necessary to obtain results with a higher level of evidence.

\section{Conclusions}

Falcotentorial meningiomas presented in $0.97 \%$ (14/1441) of meningioma patients in our single-institution series. Our study shows that a steep tentorium angle is an unfavorable factor for a supracerebellar infratentorial ap- proach, and we conclude that an occipital transtentorial/ transfalcine approach should be considered for patients with a steep tentorium or when a falcotentorial meningioma extends superiorly. Staged surgery with multiple approaches appears to be a safe strategy for large, complex falcotentorial meningiomas. Overall, as in other series, surgical treatment was associated with a high rate of permanent complications (29\%), mainly visual deficits and venous complications. The approach selection should be individualized for patients with falcotentorial meningiomas to achieve tumor growth control while avoiding approach-related complications.

\section{Acknowledgments}

We thank the staff of Neuroscience Publications at Barrow Neurological Institute for assistance with manuscript preparation.

\section{References}

1. Asari S, Maeshiro T, Tomita S, Kawauchi M, Yabuno N, Kinugasa K, et al: Meningiomas arising from the falcotentorial junction. Clinical features, neuroimaging studies, and surgical treatment. J Neurosurg 82:726-738, 1995

2. Bassiouni H, Asgari S, König HJ, Stolke D: Meningiomas of the falcotentorial junction: selection of the surgical approach according to the tumor type. Surg Neurol 69:339-349, 2008

3. Bassiouni H, Hunold A, Asgari S, Stolke D: Tentorial meningiomas: clinical results in 81 patients treated microsurgically. Neurosurgery 55:108-118, 2004

4. Behari S, Das KK, Kumar A, Mehrotra A, Srivastava AK, Sahu RN, et al: Large/giant meningiomas of posterior third ventricular region: falcotentorial or velum interpositum? Neurol India 62:290-295, 2014

5. Cardenas RJ, Javalkar V, Ezer H, Burnham J, Nanda A: Occipital interhemispheric transtentorial approach to the superior cerebellum. J Clin Neurosci 18:128-130, 2011

6. Chaynes P: Microsurgical anatomy of the great cerebral vein of Galen and its tributaries. J Neurosurg 99:1028-1038, 2003

7. DeMonte F, McDermott MW, Al-Mefty O: Al-Mefty's Meningiomas, ed 2. New York: Thieme, 2011

8. Goto T, Ohata K, Morino M, Takami T, Tsuyuguchi N, Nishio A, et al: Falcotentorial meningioma: surgical outcome in 14 patients. J Neurosurg 104:47-53, 2006

9. Hart MG, Santarius T, Kirollos RW: How I do it-pineal surgery: supracerebellar infratentorial versus occipital transtentorial. Acta Neurochir (Wien) 155:463-467, 2013

10. Hong CK, Hong JB, Park H, Moon JH, Chang JH, Lee KS, et al: Surgical treatment for falcotentorial meningiomas. Yonsei Med J 57:1022-1028, 2016

11. Kao SC, Waziri MH, Smith WL, Sato Y, Yuh WT, Franken EA Jr: MR imaging of the craniovertebral junction, cranium, and brain in children with achondroplasia. AJR Am J Roentgenol 153:565-569, 1989

12. Kaul D, Budach V, Graaf L, Gollrad J, Badakhshi H: Outcome of elderly patients with meningioma after image-guided stereotactic radiotherapy: a study of 100 cases. BioMed Res Int 2015:868401, 2015

13. Konovalov AN, Spallone A, Pitzkhelauri DI: Meningioma of the pineal region: a surgical series of 10 cases. J Neurosurg 85:586-590, 1996

14. Li D, Zhang H, Jia W, Zhang L, Zhang J, Liu W, et al: Significance of the tentorial alignment in protecting the occipital lobe with the Poppen approach for tentorial or pineal area meningiomas. World Neurosurg 108:453-459, 2017

15. Liu JK, Cohen MA: Endoscopic-assisted posterior interhemispheric retrocallosal transfalcine approach for microsurgical resection of a pineal region falcotentorial meningioma: 
operative video and technical nuances. Neurosurg Focus 40 (Video Suppl 1):V15, 2016

16. Lozier AP, Bruce JN: Meningiomas of the velum interpositum: surgical considerations. Neurosurg Focus 15(1):E11, 2003

17. Matsushima T, Rhoton AL Jr, de Oliveira E, Peace D: Microsurgical anatomy of the veins of the posterior fossa. J Neurosurg 59:63-105, 1983

18. Nowak A, Dziedzic T, Czernicki T, Kunert P, Marchel A: Falcotentorial and velum interpositum meningiomas: two distinct entities of the pineal region. Neurol Neurochir Pol 48:397-402, 2014

19. Obrador S, Soto M, Gutierrez-Diaz JA: Surgical management of tumours of the pineal region. Acta Neurochir (Wien) 34:159-171, 1976

20. Okami N, Kawamata T, Hori T, Takakura K: Surgical treatment of falcotentorial meningioma. J Clin Neurosci 8 (Suppl 1): $15-18,2001$

21. Otani N, Mori K, Wada K, Tomiyama A, Toyooka T, Takeuchi S: Multistaged, multidirectional strategy for safe removal of large meningiomas in the pineal region. Neurosurg Focus 44(4):E13, 2018

22. Pollock BE, Stafford SL, Utter A, Giannini C, Schreiner SA: Stereotactic radiosurgery provides equivalent tumor control to Simpson Grade 1 resection for patients with small- to medium-size meningiomas. Int J Radiat Oncol Biol Phys 55:1000-1005, 2003

23. Qiu B, Wang Y, Ou S, Guo Z, Wang Y: The unilateral occipital transtentorial approach for pineal region meningiomas: a report of 15 cases. Int J Neurosci 124:741-747, 2014

24. Quiñones-Hinojosa A, Chang EF, Chaichana KL, McDermott MW: Surgical considerations in the management of falcotentorial meningiomas: advantages of the bilateral occipital transtentorial/transfalcine craniotomy for large tumors. Neurosurgery 64 (5 Suppl 2):260-268, 2009

25. Raco A, Agrillo A, Ruggeri A, Gagliardi FM, Cantore G: Surgical options in the management of falcotentorial meningiomas: report of 13 cases. Surg Neurol 61:157-164, 2004

26. Rankin J: Cerebral vascular accidents in patients over the age of 60. II Prognosis. Scott Med J 2:200-215, 1957

27. Rosen CL, Ammerman JM, Sekhar LN, Bank WO: Outcome analysis of preoperative embolization in cranial base surgery. Acta Neurochir (Wien) 144:1157-1164, 2002

28. Shah AH, Patel N, Raper DM, Bregy A, Ashour R, Elhammady MS, et al: The role of preoperative embolization for intracranial meningiomas. J Neurosurg 119:364-372, 2013

29. Simpson D: The recurrence of intracranial meningiomas after surgical treatment. J Neurol Neurosurg Psychiatry 20:22-39, 1957

30. Stein BM: Surgical treatment of pineal tumors. Clin Neurosurg 26:490-510, 1979
31. Syed HR, Jean WC: A novel method to measure the tentorial angle and the implications on surgeries of the pineal region.

World Neurosurg 111:e213-e220, 2018

32. Yağmurlu K, Zaidi HA, Kalani MYS, Rhoton AL Jr, Preul MC, Spetzler RF: Anterior interhemispheric transsplenial approach to pineal region tumors: anatomical study and illustrative case. J Neurosurg 128:182-192, 2018

33. Yoshimoto K, Araki Y, Amano T, Matsumoto K, Nakamizo A, Sasaki T: Clinical features and pathophysiological mechanism of the hemianoptic complication after the occipital transtentorial approach. Clin Neurol Neurosurg 115:1250 1256,2013

34. Youssef AS, Downes AE, Agazzi S, Van Loveren HR: Life without the vein of Galen: clinical and radiographic sequelae. Clin Anat 24:776-785, 2011

35. Zaidi HA, Elhadi AM, Lei T, Preul MC, Little AS, Nakaji P: Minimally invasive endoscopic supracerebellar-infratentorial surgery of the pineal region: anatomical comparison of four variant approaches. World Neurosurg 84:257-266, 2015

36. Zhao X, Zhao D, Wu Y, Gao W, Cui H, Wang Y, et al: Meningioma in the elderly: characteristics, prognostic factors, and surgical strategy. J Clin Neurosci 56:143-149, 2018

37. Ziyal IM, Sekhar LN, Salas E, Olan WJ: Combined supra/ infratentorial-transsinus approach to large pineal region tumors. J Neurosurg 88:1050-1057, 1998

\section{Disclosures}

The authors report no conflict of interest concerning the materials or methods used in this study or the findings specified in this paper.

\section{Author Contributions}

Conception and design: Nakaji, Zhao. Acquisition of data: Zhao, Przybylowski, Borba Moreira, Gandhi. Analysis and interpretation of data: Zhao, Belykh, Tayebi Meybodi, Cavallo, Valli. Drafting the article: Zhao. Critically revising the article: Nakaji, Zhao, Belykh, Przybylowski, Wicks. Reviewed submitted version of manuscript: Nakaji. Statistical analysis: Zhao, Cavallo. Administrative/technical/material support: Nakaji. Study supervision: Nakaji.

\section{Correspondence}

Peter Nakaji: c/o Neuroscience Publications, Barrow Neurological Institute, St. Joseph's Hospital and Medical Center, Phoenix, AZ. neuropub@barrowneuro.org. 